\title{
Investigation of Charge Carriers in Doped Thiophene Oligomers through Theoretical Modeling of their UV/Vis Spectra
}

\author{
Ulrike Salzner $^{\dagger}$ \\ Bilkent University, Department of Chemistry, 06800 Bilkent, Ankara, Turkey
}

Received: January 22, 2008; Revised Manuscript Received: March 3, 2008

\begin{abstract}
The nature of the charge carriers in conducting organic polymers (COPs) is a long standing problem. Polythiophene is one of the prototypes of COPs and intensively studied. Because doping leads to changes in UV/vis spectra that are characteristic of the absorbing species, UV/vis spectra of charged thiophene oligomers with up to 25 rings were calculated with time-dependent density functional theory. The credibility of the method was established by comparing the results with a variety of theoretical levels and with experiment. Effects due to counterions $\left(\mathrm{Cl}_{3}{ }^{-}\right)$and solvent $\left(\mathrm{CH}_{2} \mathrm{Cl}_{2}\right)$ were examined. It was found that TDDFT employing hybrid functionals is accurate enough to distinguish the absorbing species. The findings offer an explanation for the experimentally observed difference in UV-spectra of medium-sized and long oligomers upon doping. As chain lengths of the oligomers increase and energy levels get closer, configuration interaction leads to additional absorption peaks in the high energy sub-band region (at around $1.5-2.5 \mathrm{eV}$ ). Thus, long oligomers do not behave differently from medium-sized ones upon doping, only their spectra are different. At low doping levels radical cations (polarons) are produced. At higher doping levels, dications that harbor weakly interacting polaron pairs are formed. Bipolarons are predicted only on very short chains or at high doping levels. There is no bipolaron binding energy and disproportionation of monocations into dications and neutral species is energetically unfavorable.
\end{abstract}

\section{Introduction}

Soon after the discovery of conducting organic polymers, ${ }^{1-9}$ electron spin resonance ESR experiments ${ }^{10}$ indicated that charge carriers in COPs must be different from those in inorganic semiconductors as the spin count was much lower than the doping level. The low spin count in conducting states of COPs was originally rationalized with bipolaron formation, which means that two charged defects occur as spinless pairs. ${ }^{11,12}$ This rationalization was challenged when thiophene oligomers ${ }^{13-38}$ (OT)s were investigated as models for polythiophene (PT). Thus although polythiophene (PT) is one of the most studied COPs, ${ }^{7,10,29,39-55}$ the doping process is still not completely understood.

The nature of the charge carriers can be investigated with optical spectroscopy. ${ }^{56}$ Neutral PT has a strong absorption band in the $\mathrm{UV}-$ vis spectrum at $2.7 \mathrm{eV} .{ }^{9}$ Upon doping in the presence of perchlorate ions, the strong interband absorption at $2.7 \mathrm{eV}$ vanishes and two new absorptions develop at lower energy. ${ }^{9}$ The development of two sub-band transitions was rationalized in terms of bipolaron formation based on Hückel-type theoretical investigations. ${ }^{9,11,12,42,57,58}$ Doping experiments on OTs in solution, however, raised doubts regarding bipolaron formation because it was shown that two sub-band transitions are consistent with radical cation (polaron) formation. ${ }^{27,38}$ In contrast, bipolarons give rise to only one sub-band transition. ${ }^{14,16-20,23,27,38}$

In most of the oligomer studies systems with up to about 8 thiophene rings were used. Becasue the properties up to this chain length scale regularly with increasing number of repeat units, a convergence of the properties toward those of polymers is usually assumed. ${ }^{22}$ Puzzling differences between "short" and "long" chains became apparent when longer doped oligomers

\footnotetext{
${ }^{\dagger}$ E-mail: salzner@fen.bilkent.edu.tr.
}

became available. The transition in properties occurs between 9 and 11 rings. ${ }^{25,26}$ Although two sub-band transitions appear also for the dodecamer (12T) upon doping, the interband absorption of the neutral oligomer decreases only to half of its original intensity (whereas it disappears completely for shorter oligomers). ${ }^{34}$ An absorption in the range of the neutral oligomer is also visible in the spectrum of lightly doped 41-thiophene (41T). ${ }^{37}$ In the case of $12 \mathrm{~T}$ this behavior was rationalized with disproportionation reactions. ${ }^{34}$ The observed spectrum upon doping is therefore attributed to a mixture of neutral $12 \mathrm{~T}$ and $12 \mathrm{~T}^{2+}$. Nonetheless the UV-spectrum of lightly doped $12 \mathrm{~T}$ shows two rather than one optical absorption, ${ }^{34}$ which should indicate the presence of $12 \mathrm{~T}^{+}$. The appearance of two absorptions for $12 \mathrm{~T}^{2+}$ was rationalized with separation of the two charges on the same chain, corresponding to two weakly interacting polarons. ${ }^{34}$

Theory offers the chance to investigate the proposed species and to predict their UV-spectra. Thus, if sufficient accuracy could be achieved, it should be possible to verify the nature of the absorbing species theoretically. Unfortunately, theoretical prediction of UV-spectra of oligomers of the required chain lengths is only possible with semiempirical methods, ${ }^{59-64}$ timedependent Hartree-Fock (TDHF), ${ }^{65-74}$ and time-dependent density functional theory (TDDFT).$^{64,69-72,75-90}$ Accurate ab initio methods like complete active space self-consistent-field/multiconfiguration second-order perturbation theory (CASPT2) or multireference perturbation theory (MRMP) are limited to systems with around $12-14 \pi$-electrons. ${ }^{91-105}$ Only one study based on CASCI/MRMP was carried out for neutral polyenes with up to 28 carbon atoms. ${ }^{99}$ Because $12 \mathrm{~T}$ has $60 \pi$-orbitals and $72 \pi$-electrons, usage of high level ab initio approaches is out of the question. Semiempirical methods have been shown to be unable to reach the required accuracy as bands have to be 


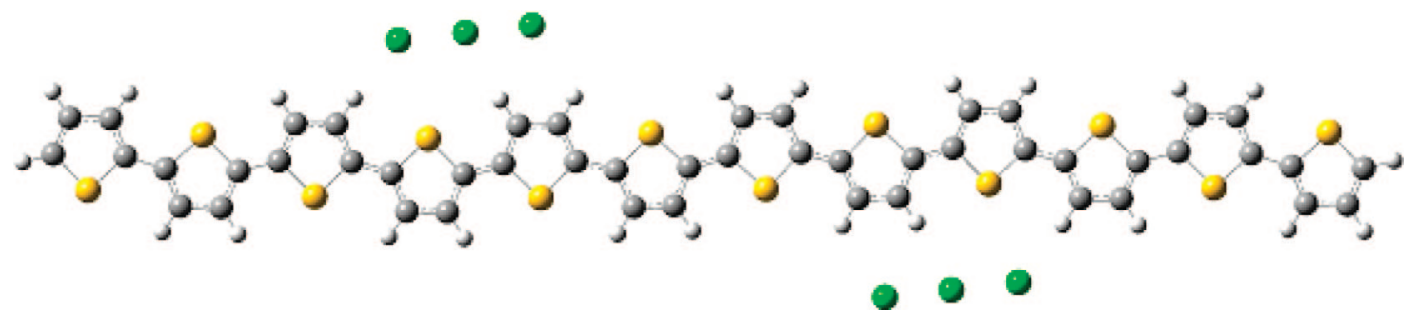

Figure 1. Minimum structure of $12 \mathrm{~T}\left(\mathrm{Cl}_{3}\right)_{2}$.

shifted by several tenths of an electronvolt up and down to match experimental data. ${ }^{59,60}$ Very accurate results can be obtained for neutral $\pi$-systems with time-dependent-Hartree-Fock (TDHF), ${ }^{73,74,106}$ but TDHF cannot be employed for doped systems because it suffers from spin-contamination for openshell species. TDDFT is also problematic as it was shown to be of limited value for neutral conjugated oligomers, increasingly underestimating the first allowed excitation energy as the chain length increases. ${ }^{70-72,75-78,81,82,87,107-109}$ For radical cations, in contrast, TDDFT performs extremely well, producing excitation energies within $0.2-0.3 \mathrm{eV}$ of the experimental values for doublet excited states. ${ }^{73,74,79,110}$ Good performance of TDDFT was also reported for dications. ${ }^{80}$

Because TDDFT was proven to be reliable for OT cations, it is interesting to note that TDDFT predicts a change in spectra when oligomers reach a length of $10-12$ rings. ${ }^{74}$ The reason for this change is that the electron configuration that gives rise to the second (higher energy) sub-band peak in the UV-spectrum starts mixing with other electron configurations and splits into two separate features. ${ }^{74}$ With increasing chain lengths the lower energy component decreases and the higher energy component increases in intensity. Thus TDDFT predicts different spectra for short and long oligomers in agreement with experimental observations. These changes are, however, associated with monocations rather than with dications. To investigate the entire doping process more thoroughly, doubly charged oligomers are modeled here with TDDFT including OTs with chain lengths up to 25 rings. In connection with results previously obtained for radical cations, it is suggested that the experimentally observed spectral changes are not due to disproportionation but due to different absorption properties of long oligothiophene radical cations.

\section{Methods}

Thiophene dication oligomers with $2-25$ rings $\left(2 \mathrm{~T}^{2+}-25 \mathrm{~T}^{2+}\right)$ were optimized as closed-shell and as open-shell (OS) species. All oligomers were kept planar, in agreement with the minimum conformations of cations ${ }^{111}$ and dications ${ }^{69}$ and of neutral oligomers in the solid state. ${ }^{112}$ Geometry optimizations were carried out with the B3P86 113,114 hybrid functional including $30 \%$ of Hartree-Fock exchange. ${ }^{115,116}$ Excited states were calculated on the B3P86-30\% ground-state geometries with the complete active space self-consistent field (CASSCF) method, ${ }^{117-120}$ with multiconfiguration quasi-degenerate perturbation theory to the second order (MCQDPT2), ${ }^{121}$ with TDB3P86-30\%, pure TDDFT (TDBP86), and TDHF, depending on chain lengths and spin state. Stevens-Basch-Krauss pseudopotentials ${ }^{122-124}$ with polarized split valence basis sets were used throughout. Test calculations with $6-31 G^{*}$ and $6-31+\mathrm{G}^{*}$ basis sets for $9 \mathrm{~T}^{+}$gave virtually identical results for the excitation energies, although all bonds are about $0.01 \AA$ shorter with all-electron basis sets. Detailed discussions about the TDDFT methods can be found in earlier publications. ${ }^{71-74,115,116}$
Solvent effects were examined at the TDB3P86-30\% level with the polarized continuum model $(\mathrm{PCM})^{125}$ and $\mathrm{CH}_{2} \mathrm{Cl}_{2}$ as the solvent. The MCQDPT2 calculations were carried out with the GAMESS program, ${ }^{126}$ CASSCF calculations were done with GAMESS $^{126}$ and Gaussian 03, ${ }^{127}$ all other calculations were done with Gaussian 03. ${ }^{127}$

Throughout this work theoretical vertical excitation energies are compared to experimental $\lambda_{\max }$ values. This is an approximation as the vibronic structure of the absorption spectra is ignored. ${ }^{81,82}$ Such an approach is justified in the present context because vibronically resolved spectra are unavailable for charged oligothiophenes and because the error for neutral systems is relatively small. The effect of geometry changes upon excitation can be estimated as follows: because the low lying excitation energies of $\pi$-systems involve HOMO-LUMO transitions, excitation increases double bond lengths and decreases single bond lengths. The $0-0$ transition can therefore not be vertical. The vibrational peak for ring deformation in thiophene oligomers is analogous to the $\mathrm{C}=\mathrm{C}$ stretching vibration of polyenes, ${ }^{128}$ which produces fairly regular spacings of about $0.2 \mathrm{eV}$. Spectra of long polyenes show that $\lambda_{\max }$ is close to the second or third peak of the vibrational progression. ${ }^{129}$ Solution spectra of thiophene oligomers ${ }^{130}$ are less resolved but show similar features. Therefore, $\lambda_{\max }$ has a $0.2-0.4$ eV higher energy than the $0-0$ transition. As shown by Dierksen and Grimme, the vertical excitation is about $0.2-0.4 \mathrm{eV}$ larger in energy than the theoretical $0-0$ transition. ${ }^{82}$ Any change in the vibrational energies due to charging decreases with increasing chain length and tends to be smaller for cations because electron removal weakens double bonds. Therefore, it can be expected that vertical excitation energies are very close to $\lambda_{\max }$ for neutral and charged long thiophene oligomers.

Oligomers with counterions were fully optimized with counterions above and in the plane of the carbon backbone. Lower energies are obtained when $\mathrm{Cl}_{3}{ }^{-}$lies in the plane of the oligomer next to the positively charged $\mathrm{H}$-atoms. Inclusion of solvent increases the distance between counterion and oligomer by about $0.02 \AA$. The geometry of the oligothiophene changes only slightly. For dications, the distance between the counterions was determined by moving them along the backbone and fully optimizing each local minimum. The structure shown in Figure 1 is the global minimum for $12 \mathrm{~T}\left(\mathrm{Cl}_{3}\right)_{2}$. Even if the counterions are next to the central rings, the singlet biradical is lower in energy then the closed-shell singlet.

To assign the nature of the excited states of neutral and charged systems of various chain lengths, Pariser's notation ${ }^{131}$ is used. As shown in Scheme 1, the orbital numbering assigned for the neutral form will be used also for charged systems. The major absorption peaks of medium-sized oligomers arise from the electron configurations indicated in Scheme 1. Bithiophene and oligomers with more than 8 rings exhibit additional peaks involving transitions between lower lying occupied and higher lying unoccupied orbitals. 


\section{SCHEME 1}
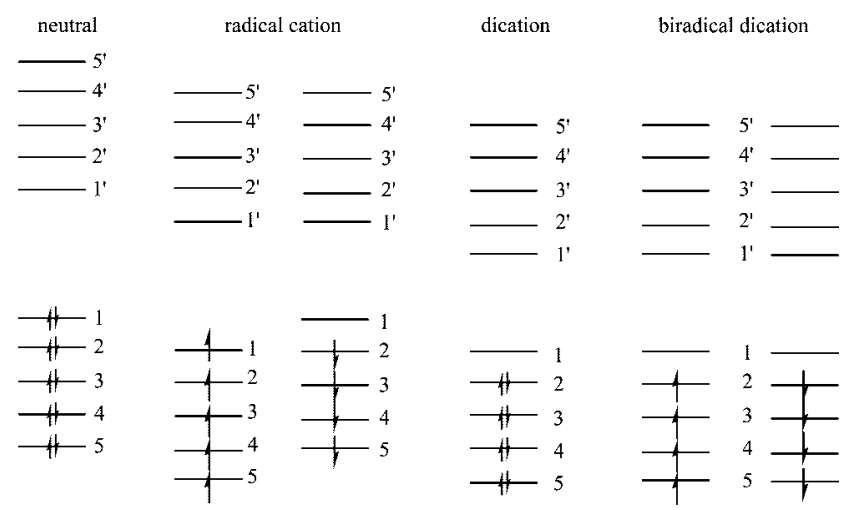

$\underset{1 \rightarrow 1^{\prime}}{\operatorname{HOMO}}$

$$
2 \rightarrow 1
$$

HOMO-LUMO

HOMO-LUMO $2 \rightarrow 1$
$3 \rightarrow 1$

\section{Results}

Radical Cations. Spectra of oligothiophene radical cations were investigated in detail in a previous paper $^{74}$ where the reliability of TDB3P86-30\% results was established by comparison with CASPT2 calculations ${ }^{95,97}$ for $2 \mathrm{~T}^{+}$and $3 \mathrm{~T}^{+}$, and for longer oligomers by comparison with experiment. In Figures 2 and 3, TDB3P86-30\% predictions regarding the first three allowed singlet states below the absorption edge of the corresponding neutral oligomers are summarized. Figure 2 shows the development of the excitation energies with chain length of up to 25 thiophene rings. Up to $6 \mathrm{~T}^{+}, \mathrm{E} 3$ is absent appearing for the first time for $8 \mathrm{~T}^{+}$as a weak feature slightly below the band edge of 8T. E3 and E2 decrease in energy with chain length in a parallel fashion and converge to around 2.0 and $1.1 \mathrm{eV}$, respectively. E1 decreases somewhat faster and is predicted to appear below $0.2 \mathrm{eV}$ for oligomers longer than 20 rings. $\mathrm{E} 3$ of the cations is located at precisely the same energy as $\lambda_{\max }$ of the corresponding neutral oligomers, if both are calculated at the same level of theory. Because it is known that $\lambda_{\max }$ of the neutral oligomers is underestimated at TDB3P86$30 \%$, the question arises whether E3 is also predicted too low. In the absence of high level benchmark calculations, it can only be concluded here that for long oligothiophene cations there is a third strong absorption at or somewhat below the band edge of the neutral species.

In Figure 3, the development of the oscillator of the three sub-band transitions is plotted versus number of thiophene rings.

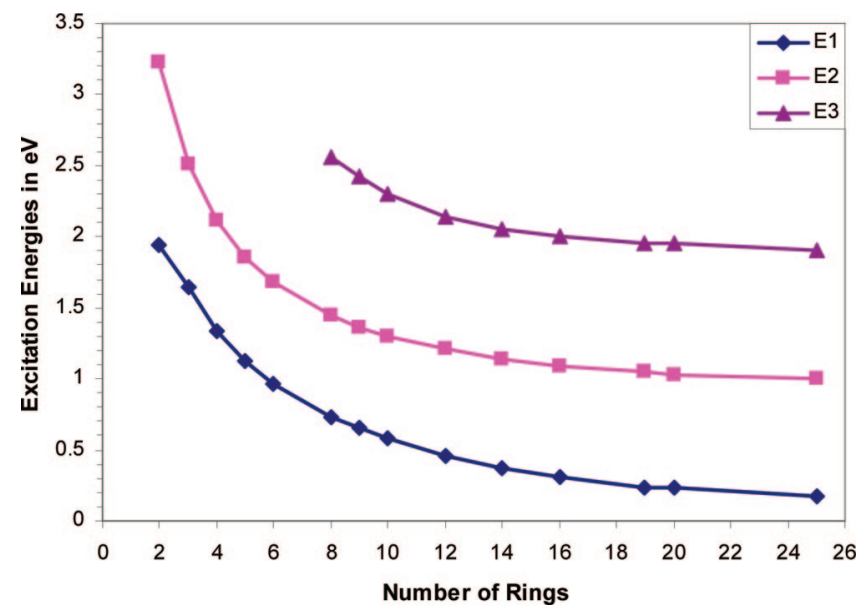

Figure 2. Development of the first absorption energies for $2 \mathrm{~T}^{+}$through $25 \mathrm{~T}^{+}$.

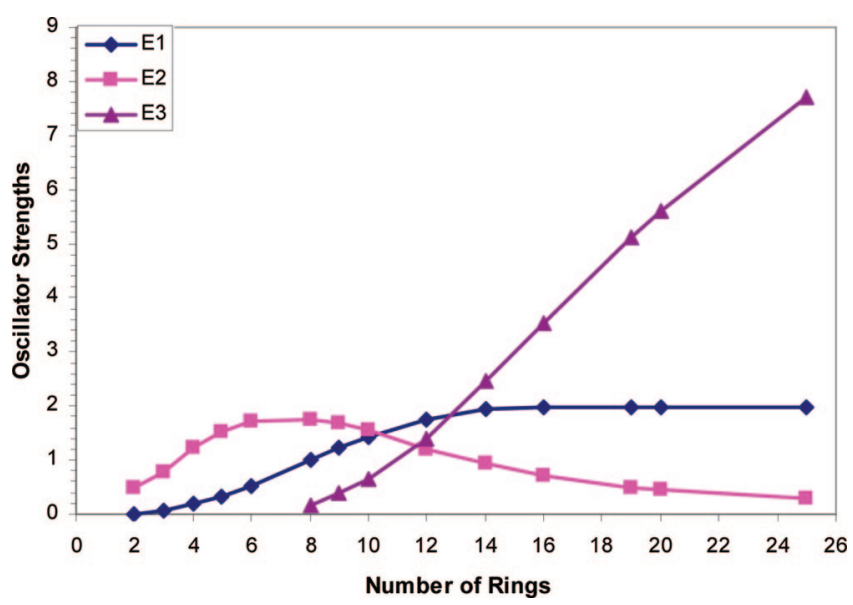

Figure 3. Oscillator strength of the first three allowed singlet transitions of $2 \mathrm{~T}^{+}$through $25 \mathrm{~T}^{+}$versus chain lengths.

For short oligomers, up to $6 \mathrm{~T}^{+}$, TDB3P86-30\% predicts the high energy sub-band transition to be stronger and growing faster in oscillator strength with increasing chain length than the low energy one. At a chain length of 8 rings, a third absorption appears and the oscillator strength of E2 levels off. That oscillator strengths of E2 and E3 are inversely related is caused by the fact that both peaks arise from 1 to $1^{\prime}$ transitions (compare Scheme 1) which interact with other electronic configurations. ${ }^{74}$ As a result, oscillator strength shifts from E2 to E3 with increasing chain length. For $10 \mathrm{~T}^{+} \mathrm{E} 1$ and $\mathrm{E} 2$ are predicted to have the same oscillator strength. For $12 \mathrm{~T}^{+} \mathrm{E} 1$ is strongest and $\mathrm{E} 2$ and $\mathrm{E} 3$ are predicted to have the same oscillator strength. For longer oligomers, E3 is dominant, E2 tends to vanish, and the oscillator strength of E1 becomes constant.

Dications: Singlet States (Bipolarons). TDB3P86-30\% underestimates the excited states of neutral OTs ${ }^{71,72}$ but provides accurate results for radical cations. ${ }^{74}$ Likewise agreement of TDDFT spectra of thienylene vinylene oligomer dications with experiment was reported. ${ }^{80}$ To further investigate whether TDDFT can handle dications, bithiophene dication spectra were obtained with TDHF, TDBP86, TDB3P86-30\%, CASSCF and MCQDPT2 calculations including all ten $\pi$-electrons and $\pi$-orbitals. All levels of theory predict four excitations below the band gap of $2 \mathrm{~T}$ that arise mainly from the following electronic transitions: $2-1,3-1,4-1$, and 5-1 (compare Scheme 1). 3-1 and 5-1 are symmetry forbidden and have no oscillator strength. CASSCF calculations show that the latter has double excitation character. $2-1$ is the HOMO-LUMO transition of the dication and is lowest in energy but has low oscillator strength for $2 \mathrm{~T}^{2+}$. The third excited state $(4-1)$ is predicted to be the observable state in the spectrum of the bithiophene dication. Energies and oscillator strength where available are summarized at different levels of theory in Table 1 . Because there are no experimental data for $2 \mathrm{~T}^{2+}$, the MCQDPT2 results serve as the benchmark. The trends are as expected. TDHF and CASSCF overestimate all excitations energies, pure DFT (TDBP86) underestimates them. The agreement between TDB3P86-30\% and MCQDPT2 is remarkable with deviations between 0.07 and $0.17 \mathrm{eV}$.

Unfortunately, bithiophene is the longest OT that can be treated with a complete active space including all $\pi$-electrons and orbitals. Bithiophene, however, is too short to detect problems that might arise upon increasing chain length at the TDB3P86-30\% level. The underestimation of excitation energies with TDDFT of neutral $\pi$-systems is attributed to incomplete cancelation of self-interaction. ${ }^{77,78,132,133}$ Because HF theory is 
TABLE 1: First Four Excitation Energies of $2 \mathrm{~T}^{2+}$ in $\mathrm{eV}$ (Oscillator Strengths in Parentheses)

\begin{tabular}{lllllr}
\hline state & \multicolumn{1}{c}{ TDHF } & TDBP86 & TDB3P86-30\% & CASSCF & MCQDPT2 \\
\hline $2-1$ & $3.26(0.14)$ & $1.77(0.01)$ & $2.23(0.02)$ & 2.69 & 2.16 \\
$3-1$ & $3.45(0)$ & $1.94(0)$ & $2.42(0)$ & 2.80 & 2.55 \\
$4-1$ & $4.17(0.81)$ & $3.66(0.53)$ & $3.84(0.64)$ & 3.72 & 3.67 \\
$5-1$ & $5.77(0)$ & $3.69(0)$ & $4.34(0)$ & 4.43 & 4.23
\end{tabular}

free of the self-interaction error and tends to overestimate excitation energies, a comparison of TDHF and TDDFT excitation energies can be used to detect possible deterioration of the TDDFT results with increasing chain length. In Figures 4, 2and 1 excitation energies of $4 \mathrm{~T}^{2+}$ through $25 \mathrm{~T}^{2+}$ at the TDBP86, TDB3P86-30\% and TDHF levels are compared. Experimental values are taken form ref 34. It is seen in Figure 4 that there is no indication of an underestimation of excitation energies at the TDB3P86-30\% level compared to TDHF or experiment. The erratic behavior of the TDHF data at very long chain lengths is due to state splitting starting at $20 \mathrm{~T}^{2+}$. Furthermore inclusion of HF exchange in TDDFT calculations is of little consequence for the first excitation energies as TDB3P86-30\% and TDBP86 results almost coincide. Thus, like for cations, TDDFT produces reliable results for dications even in the long chain limit.

For $8 \mathrm{~T}^{2+}$, some very weak features appear in the region of the main transition of neutral 8T. One of these transitions, which arises from $1-3^{\prime}$ and $2-2^{\prime}$ transitions grows rapidly in intensity with increasing chain length. Excitation energies at the TDB3P86$30 \%$ level are summarized for $2 \mathrm{~T}^{2+}-25 \mathrm{~T}^{2+}$ in Table 2 . Included are all excitations below the TDHF band gap of the corresponding neutral oligomer that have oscillator strengths above 0.1 . The development of the spectra is shown in Figure 5 for $8 \mathrm{~T}^{2+}-25 \mathrm{~T}^{2+}$. Apart from a peak splitting for $3 \mathrm{~T}^{2+}$, TDB3P86$30 \%$ predicts one strong absorption for oligomers up to 9 rings that arises from $2-1$ electronic transitions. For $12 \mathrm{~T}^{2+}$ a second absorption of considerable oscillator strength is calculated, and with increasing chain lengths, starting at $20 \mathrm{~T}^{2+}$ this peak becomes dominant.

Test calculations at the TDHF and TBP86 levels also produce additional peaks, but the chain length for the first appearance and exact position of these absorptions depends on the amount of HF exchange. TDBP86 (pure DFT) requires the shortest chains lengths and predicts the lowest energy. TDHF requires the longest chains and predicts the highest energies. At all three levels of theory the additional feature appears very close to the

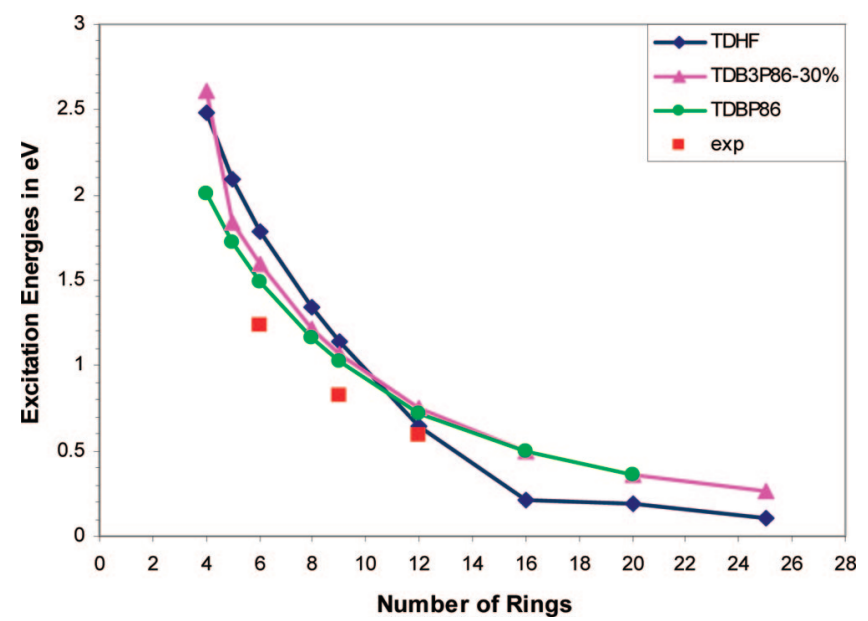

Figure 4. Excitation energies to the first excited state of $4 \mathrm{~T}^{2+}$ through $25 \mathrm{~T}^{2+}$ at TDHF, TDBP86, and TDB3P86-30\%. Experimental data are from ref 34 . $1-1^{\prime}$ absorption of the corresponding neutral system, just like for monocations. Because the new peaks arise from configuration interaction due to energy levels that get closer with chain length increase and because DFT with hybrid functionals is the only of the three methods that predicts relative energy levels in agreement with photoelectron spectroscopy, ${ }^{134}$ using the hybrid functional is the most plausible choice. The additional peak was also predicted by Grozema for thienylene vinylene dications ${ }^{80}$ and by Gao et al. for $12 \mathrm{~T}^{2+} .^{90}$ With B3LYP/6-31G* the peak appears at $1.94 \mathrm{eV},{ }^{90}$ a little lower in energy than at B3P86$30 \%$ where it occurs at $2.10 \mathrm{eV}$. Thus, there is no certainty about the exact position of this peak. The best guess is at present that the new peak occurs at about $0.3 \pm 0.3 \mathrm{eV}$ below the absorption of the corresponding neutral species.

Dications: Biradicals (Polaron Pairs). In chemists' terminology bipolarons correspond to closed-shell singlet states, two polarons on the same chain correspond to singlet or triplets biradicals. Due to large spin-contamination for open-shell systems, comparison with HF theory is not possible and only DFT-hybrid results will be employed from here on. Unrestricted B3P86-30\% calculations predict open-shell singlet ground states starting with $4 \mathrm{~T}^{2+}$, a little earlier than B3LYP/6-31G*, 100 which uses $10 \%$ less $\mathrm{HF}$ exchange. The expectation value of the spin operator is 0.34 for $4 \mathrm{~T},{ }^{2+}$ and 0.84 for $6 \mathrm{~T}^{2+}$ and increases to 1.08 for $25 \mathrm{~T}^{2+}$. This suggests that ground states of mediumsized and long dications are mixtures of singlet and triplet states, corresponding to two weakly interacting polarons. This is reflected in the geometry changes (Figures 6 and 7) of closedshell $20 \mathrm{~T}^{2+}$ and open-shell optimized $25 \mathrm{~T}^{2+}$. Even the closedshell calculation predicts a tendency for defect separation for extended systems, but the effect is much more pronounced with an open-shell treatment. The biradical shows two regions of strong geometry distortion and very little change in bond lengths in the center part of the $25 \mathrm{~T}^{2+}$ biradical in singlet and triplet states.

For short and medium-sized chains, singlets are more stable than triplets. ${ }^{100}$ Singlet biradical and triplet of $25 \mathrm{~T}^{2+}$ are energetically degenerate, and their bond lengths are identical. Figure 7 shows that even for $25 \mathrm{~T}^{2+}$ there are slight changes in bond lengths in the middle of the chain. Thus polarons are localized toward opposite ends of the chain but they are not totally separated.

TABLE 2: Excitation Energies in $\mathrm{eV}$ of Closed-Shell $2 \mathrm{~T}^{2+}-25 \mathrm{~T}^{2+}$ at the TDB3P86-30\% Level of Theory (Oscillator Strengths in Parentheses)

\begin{tabular}{lccccc}
\hline & E1 & E2 & E3 & E4 & E5 \\
\hline 2 & $3.84(0.64)$ & & & & \\
3 & $2.62(0.68)$ & $3.02(0.56)$ & & & \\
4 & $2.19(1.62)$ & $2.97(0.21)$ & & & \\
5 & $1.84(2.23)$ & $2.98(0.17)$ & & & \\
6 & $1.59(2.78)$ & $2.98(0.16)$ & & & \\
8 & $1.22(3.69)$ & $2.67(0.17)$ & & & \\
9 & $1.07(4.02)$ & $2.46(0.33)$ & $2.73(0.11)$ & & \\
12 & $0.75(4.34)$ & $2.10(1.34)$ & $2.38(0.13)$ & & \\
$12-\left(\mathrm{Cl}_{3}\right)_{2}$ & $0.89(4.60)$ & $1.51(0.13)$ & $2.28(0.34)$ & $2.30(0.13)$ & $2.52(0.36)$ \\
$12-\left(\mathrm{Cl}_{3}\right)_{2}$ & $0.75(4.87)$ & $1.48(0.10)$ & $2.31(0.43)$ & & $2.42(0.50)$ \\
$\left(\mathrm{in} \mathrm{CH}_{2} \mathrm{Cl}_{2}\right)$ & & & & & \\
16 & $0.50(4.11)$ & $0.97(0.19)$ & $1.93(3.09)$ & $2.61(0.22)$ & \\
20 & $0.36(3.99)$ & $0.77(0.36)$ & $1.89(4.57)$ & $2.43(0.21)$ & $2.49(0.30)$ \\
25 & $0.26(3.68)$ & $0.61(0.37)$ & $1.84(6.29)$ & $2.01(0.16)$ &
\end{tabular}




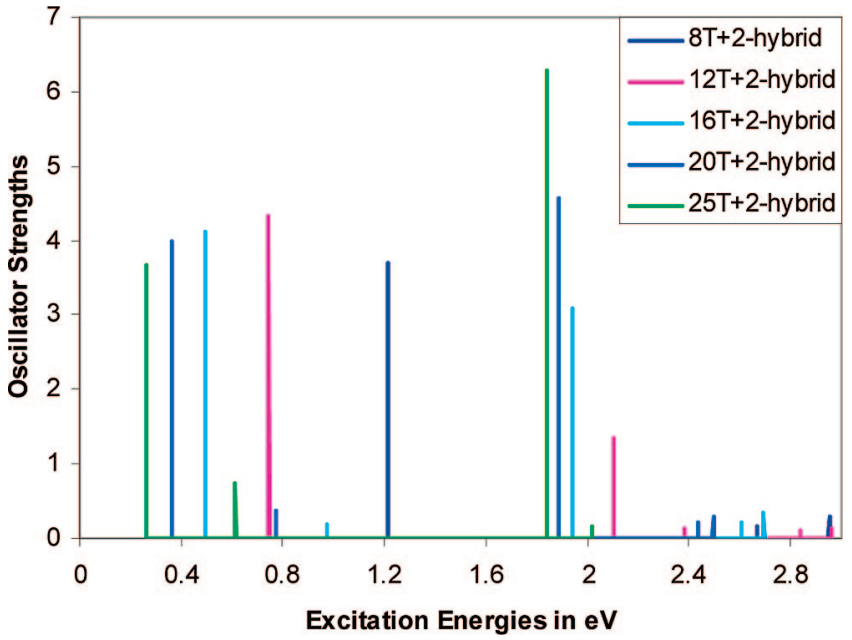

Figure 5. Sub-band absorptions for long OT dications at the TDB3P86$30 \%$ level of theory.



Figure 6. Bond length changes in $20 \mathrm{~T}^{2+}$ (closed-shell).

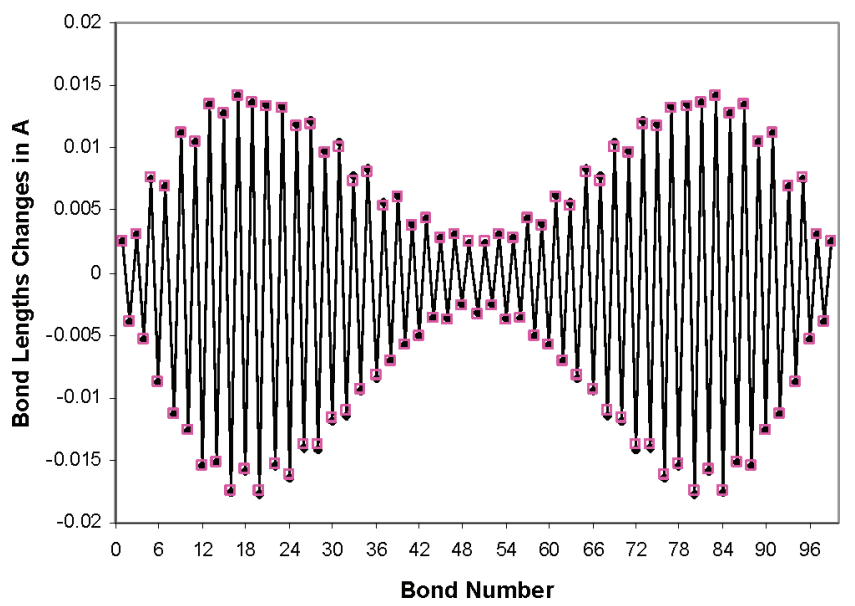

Figure 7. Bond length changes compared to neutral 25T for openshell singlet and triplet states of $25 \mathrm{~T}^{2+}$.

Although closed shell dications have only up to two strong sub-band transitions, singlet and triplet biradicals have four and probably more as chain lengths grow. Most transitions are multiconfigurational. Excitation energies at the TDB3P86-30\% level are summarized for open-shell biradicals of $4 \mathrm{~T}^{2+}-25 \mathrm{~T}^{2+}$ in Table 3. Included are all excitations below the TDHF band gap of the corresponding neutral oligomer at that have oscillator strengths above 0.1 .

In Figure 8 comparison of theoretical and experimental 9T ${ }^{2+}$ spectra shows that only the biradical has peaks in the region
TABLE 3: Excitation Energies of Open-Shell $4 \mathrm{~T}^{2+}-25 \mathrm{~T}^{2+}$ at the TDB3P86-30\% Level of Theory (Oscillator Strengths in Parentheses)

\begin{tabular}{lccccc}
\hline & E1 & E2 & E3 & E4 & E5 \\
\hline 4 & $1.88(0.37)$ & $2.24(1.11)$ & $3.04(0.15)$ & & \\
6 & $1.40(1.44)$ & $1.80(0.87)$ & $2.09(0.10)$ & $2.23(0.26)$ & \\
8 & $1.10(2.01)$ & $1.57(0.64)$ & $1.87(0.93)$ & & \\
9 & $1.00(2.21)$ & $1.48(0.53)$ & $1.77(1.21)$ & $2.03(0.21)$ & \\
12 & $0.77(2.69)$ & $1.26(0.18)$ & $1.53(1.08)$ & $1.61(1.27)$ & $1.79(0.25)$ \\
$12-\left(\mathrm{Cl}_{3}\right)_{2}$ & $0.88(2.77)$ & $1.32(0.65)$ & $1.56(0.88)$ & $1.79(0.69)$ & \\
16 & $0.56(3.16)$ & $1.37(2.11)$ & $1.46(1.19)$ & $1.58(0.11)$ & $2.48(0.79)$ \\
20 & $0.42(3.41)$ & $0.78(0.30)$ & $1.27(1.91)$ & $1.35(1.19)$ & $1.59(0.13)$ \\
& $1.96(0.19)$ & $2.23(0.29)$ & $2.25(1.57)$ & & \\
25 & $0.29(3.44)$ & $0.59(0.75)$ & $1.15(1.03)$ & $1.23(1.52)$ & $1.42(0.15)$
\end{tabular}

where experiment shows absorption. This confirms, together with symmetry breaking and energy lowering, that dications harbor polaron pairs rather than bipolarons.

As an example, for longer chains, sub-band absorptions are shown for $12 \mathrm{~T}^{2+}$ singlet and singlet biradical in Figure 9. Like for $9 \mathrm{~T}^{2+}$ the first peak of the closed-shell dication (bipolaron) appears at a similar energy as that of open-shell $12 \mathrm{~T}^{2+}$. The additional peak of the closed-singlet state at the same energy as $\lambda_{\max }$ of neutral $12 \mathrm{~T}$ disappears for the biradical. Another change in the spectrum is predicted in the region around 1.6 $\mathrm{eV}$ where the biradical has, in agreement with experiment, several strong absorptions that are absent from the closed-shell singlet spectrum. Absorption at almost the same energies was reported by Gao et al. ${ }^{90}$ at TDUB3LYP. However, at TDUB3LYP there is only one peak at $1.60 \mathrm{eV}$ and its oscillator strength is about the sum of those of the two peaks at 1.53 and $1.61 \mathrm{eV}$ with TDUB3P86-30\%. Similar to the case for the radical cations, ${ }^{74}$ certain peak splittings are method and chain length dependent and the peaks occur so close to each other that they are probably not seen as separate absorptions in experimental spectra.

The development of excitation energies and oscillator strengths for biradicals with increasing chain lengths is shown in Figures 10 and 11 . The states are assigned according to the nomenclature in Scheme 1. The first sub-band peak of open-shell dications arises from $2-1$ and $3-1$ transitions. Starting with $12 \mathrm{~T}^{2+}$, the first excited state is dominated by the $2-1$ transition. The excitation energies to this state are almost identical to those of



Figure 8. TDB3P86-30\% gas phase spectrum of closed and openshell (OS) $9 \mathrm{~T}^{2+}$ compared to the experimental spectrum of $9 \mathrm{~T}^{2+}$ in $\mathrm{CH}_{2} \mathrm{Cl}_{2}$ in the presence of thianthrenium perchlorate. ${ }^{34}$ (The oscillator strengths given to the experimental peaks are arbitrary and reflect only the relative heights of the peaks.) 




Figure 9. Difference in spectra of $12 \mathrm{~T}, 12 \mathrm{~T}^{2+}$ singlet and biradical (OS), and experiment. ${ }^{34}$ (The oscillator strengths given to the experimental peaks are arbitrary and reflect only the relative heights of the peaks.)

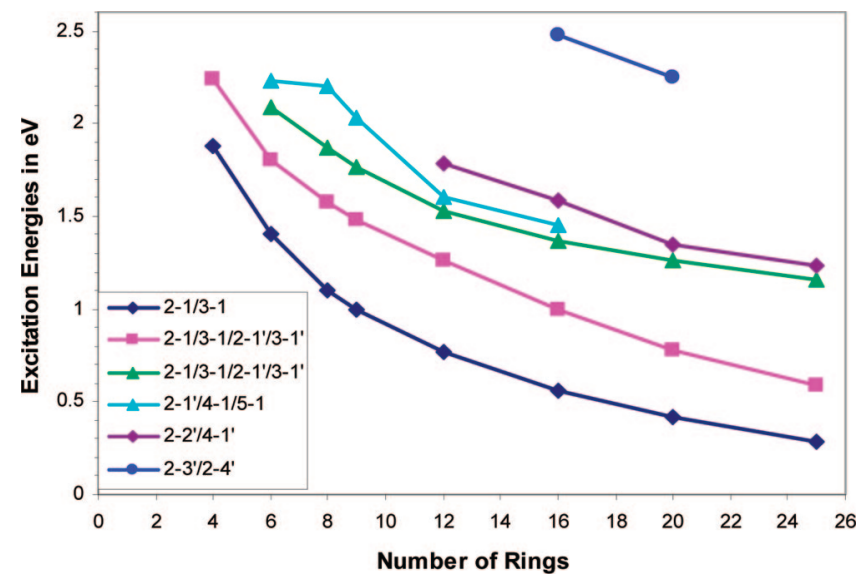

Figure 10. Sub-band excitation energies of singlet biradicals including $4 \mathrm{~T}^{2+}-25 \mathrm{~T}^{2+}$.

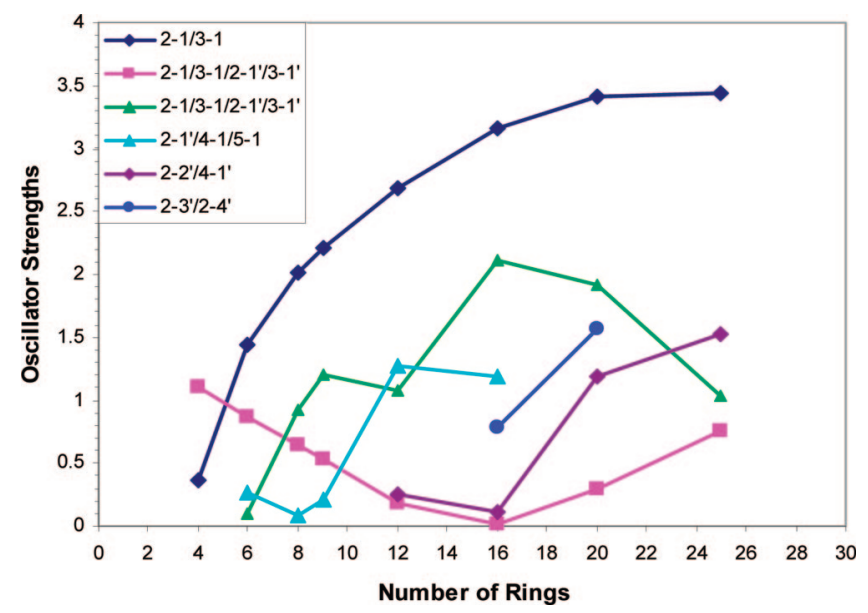

Figure 11. Oscillator strengths of the excitations of singlet biradicals including $4 \mathrm{~T}^{2+}-25 \mathrm{~T}^{2+}$.

the closed-shell dications. With the exception of the tetramer, the first peak has the highest oscillator strength. The second peak arises from four electron configurations of varying contribution. The oscillator strength goes almost through zero as the contribution from 2 to 1 declines and rises again as 3-1 becomes dominant. Assignment of the higher lying peaks gets more and more difficult as the configuration interaction gets increasingly complicated. That excitation energies and oscillator

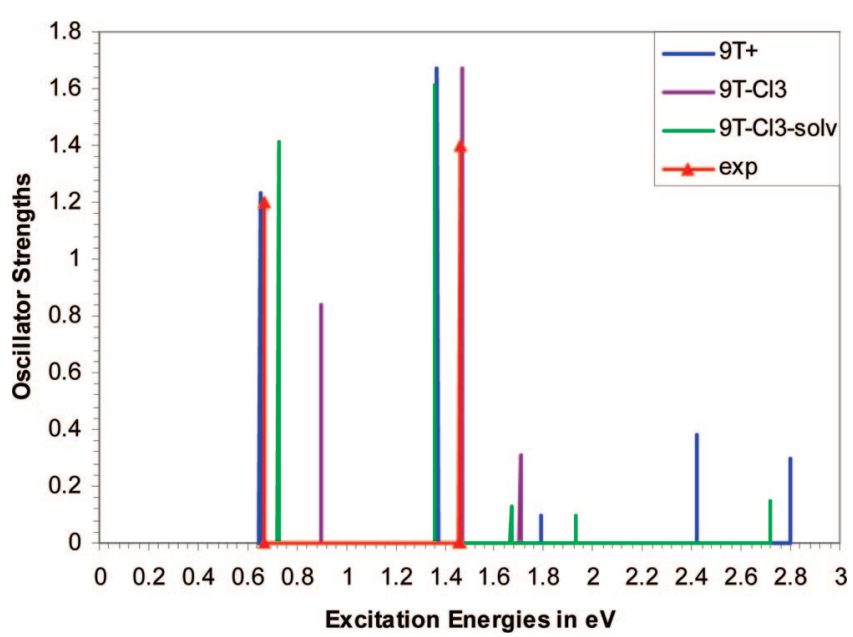

Figure 12. TDB3P86-30\% gas phase spectrum of $9 \mathrm{~T}^{+}, 9 \mathrm{~T}-\mathrm{Cl}_{3}$, and solution (solvent $=\mathrm{CH}_{2} \mathrm{Cl}_{2}$ ) spectrum of 9T- $\mathrm{Cl}_{3}$ compared to the measured $\mathrm{UV}$-spectrum of $9 \mathrm{~T}^{+}$in $\mathrm{CH}_{2} \mathrm{Cl}_{2}$ in the presence of thianthrenium perchlorate. ${ }^{34}$ (The oscillator strengths given to the experimental peaks are arbitrary and reflect only the relative heights of the peaks.)

strengths do not change smoothly with chain length is caused by the varying contributions of the individual electronic transitions. Noteworthy is the highest energy absorption that appears only for the long oligomers $16 \mathrm{~T}^{2+}$ and $20 \mathrm{~T}^{2+}$ (it will most likely also be found for $25 \mathrm{~T}^{2+}$, but the present computational resources are insufficient as about 35 excited states will have to be calculated). This high energy sub-band transition seems to gain oscillator strengths rapidly with increasing chain length. This is reminiscent of the monocations and singlet dications that also develop a strong high energy sub-band feature at long chain length.

Influence of Solvent and Counterions. 9T, ${ }^{74} 12 \mathrm{~T}$, and $13 \mathrm{~T}^{74}$ were investigated in the presence of one and two $\mathrm{Cl}_{3}{ }^{-}$ions and $\mathrm{CH}_{2} \mathrm{Cl}_{2}$ as solvent. In general, counterions shift excitation energies to higher values whereas solvent has the opposite effect. This is demonstrated for $9 \mathrm{~T}^{+}$(gas phase), $9 \mathrm{~T}-\mathrm{Cl}_{3}$ (gas phase), and $9 \mathrm{~T}-\mathrm{Cl}_{3}$ (in $\mathrm{CH}_{2} \mathrm{Cl}_{2}$ ) in Figure 12. Experimental data are taken from ref 34 It is clear from this figure that data obtained on naked ions in the gas phase differ hardly from those in the presence of counterion and solvent for medium sized oligomers. The counterion alone causes a blue shift that is reversed by the solvent. Only the two weak peaks in the high energy region are affected more strongly. The match between theoretical and experimental excitation energies with is very good with differences of $\sim 0.1 \mathrm{eV}$.

In Figure 13 counterion and solvent effects are shown for $13 \mathrm{~T}^{74}$ and compared to experimental data of $12 \mathrm{~T}$. 13T was used because odd-numbered chains remain symmetric in the presence of counterions. This does not influence the results much because excitation energies of neutral and ionic 12T and 13T species differ by only up to $0.05 \mathrm{eV}$. Like for $9 \mathrm{~T}^{+}$, counterion and solvent have opposite effects on peak positions. Overall a blue shift is obtained with respect to the gas phase spectrum. The effect of counterion and solvent is stronger on the higher energy sub-band peaks, which split into several features. Comparison with the experimental data on the early doping stage of $12 \mathrm{~T}^{34}$ shows that agreement between theory and experiment is improved in the presence of counterion and solvent. The biggest difference is the underestimation of the third excitation energy by $0.3 \mathrm{eV}$.

Counter ions and solvent cause a small red shift of the peaks predicted for open-shell $12 \mathrm{~T}^{2+}$. Here inclusion of counterion and solvent decreases the agreement between theory and 


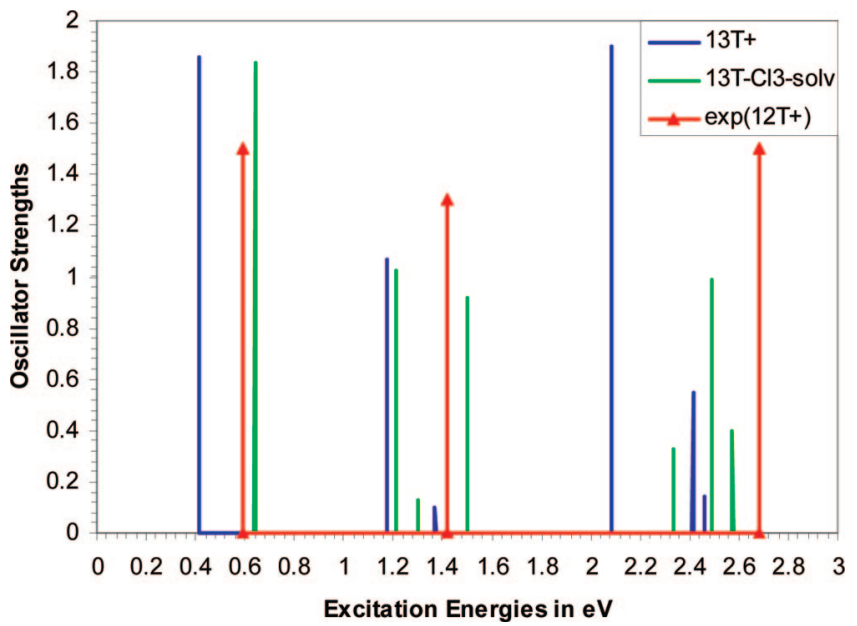

Figure 13. TDB3P86-30\% gas phase spectrum of $13 \mathrm{~T}^{+}$, and solution (solvent $=\mathrm{CH}_{2} \mathrm{Cl}_{2}$ ) spectrum of $13 \mathrm{~T}-\mathrm{Cl}_{3}$ compared to the experimental spectrum of $12 \mathrm{~T}^{+}$in $\mathrm{CH}_{2} \mathrm{Cl}_{2}$ in the presence of thianthrenium perchlorate. ${ }^{34}$ (The oscillator strengths given to the experimental peaks are arbitrary and reflect only the relative heights of the peaks.)

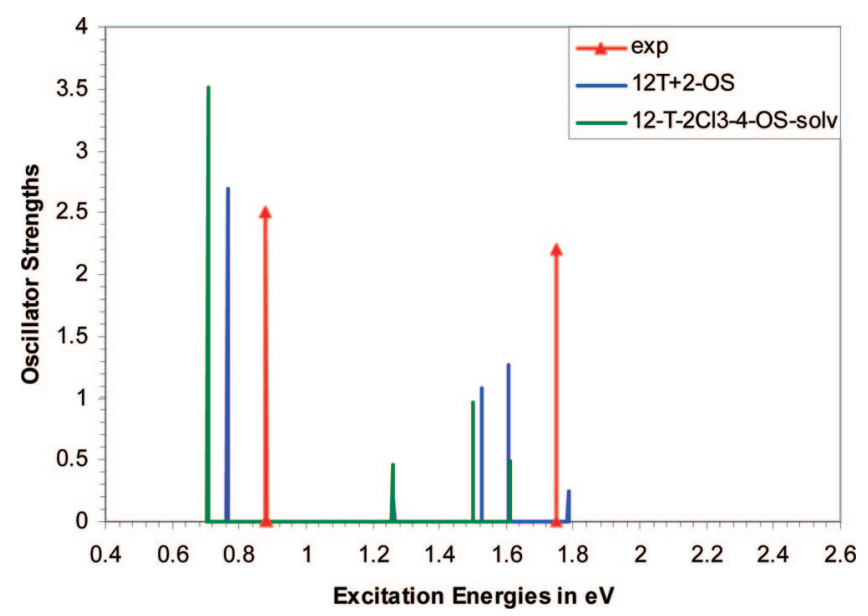

Figure 14. UV-spectra of open-shell $12 \mathrm{~T}^{2+}$ and $12 \mathrm{~T}\left(\mathrm{Cl}_{3}\right)_{2}$. (The oscillator strengths given to the experimental peaks are arbitrary and reflect only the relative heights of the peaks.)

experiment slightly as visible in Figure 14. Theoretical and experimental peak position differ by $0.17 \mathrm{eV}$ for the first peaks and the strongest of the three peaks at around $1.5 \mathrm{eV}$ lies 0.35 $\mathrm{eV}$ below the experimental absorption.

\section{Discussion}

In their 1998 paper van Haare et al. ${ }^{34}$ report UV/vis spectra of 6T, 9T, and 12T during doping experiments. They observed that although the strong absorption of the neutral species disappears upon doping for 9T, it is reduced only to half-its original size for $12 \mathrm{~T}$. There were therefore three peaks in the spectrum as opposed to the expected two. In addition, the spectrum of $12 \mathrm{~T}$ changed over time. To explain the unexpected results, van Haare et al. suggested that long chains like $12 \mathrm{~T}$ form dications in a single step, so that the observed spectrum is actually due to a mixture of $12 \mathrm{~T}^{2+}$ and neutral $12 \mathrm{~T}$ rather than to $12 \mathrm{~T}^{+}$. This would leave half of the $12 \mathrm{~T}$ chains in a neutral state, accounting for the reduction of the neutral absorption to half-its original size. However, the low energy part of the spectrum shows two sub-band transitions, which are usually indicative of radical cation formation. This was accounted for by proposing the formation of separate polarons on one chain, so that $12 \mathrm{~T}^{2+}$ behaves spectroscopically like $6 \mathrm{~T}^{+}$.

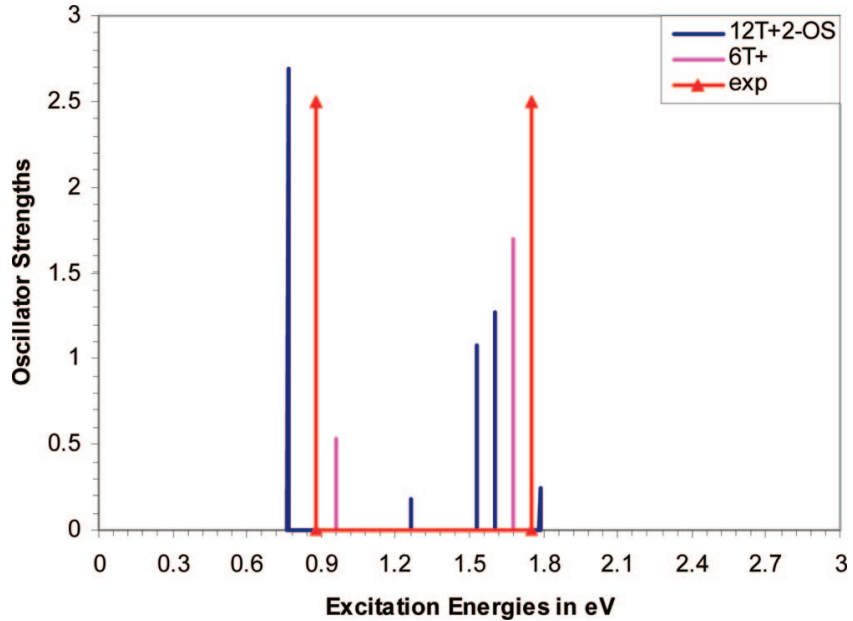

Figure 15. Comparison of spectra of $6 \mathrm{~T}^{+}$and $12 \mathrm{~T}^{2+}$ (biradical) with the experimental spectrum at an early doping stage of 12T. (The oscillator strengths given to the experimental peaks are arbitrary and reflect only the relative heights of the peaks.)

Spectra of very long oligothiophene dications were calculated here at high levels of theory for the first time. The important observation regarding the results presented in the previous sections and in a previous paper ${ }^{74}$ is that oligothiophene cations and dications with more than 9 rings exhibit additional subband transitions in the region of $\lambda_{\max }$ of the corresponding neutral species. Thus, the experimentally observed presence of an absorption in that region for $12 \mathrm{~T}$ upon doping is consistent with formation of $12 \mathrm{~T}^{+}$without invoking disproportionation.

The accuracy of the theoretical results is very good for the low energy sub-band transitions, but the position of the high energy peaks is not certain enough to be completely sure whether it explains the experimental findings. To test the assumption that spectra open-shell dications are similar to those of cations of half the chain length, excitation energies of $6 \mathrm{~T}^{+}$ and $12 \mathrm{~T}^{2+}, 8 \mathrm{~T}^{+}$and $16 \mathrm{~T}^{2+}$, and $10 \mathrm{~T}^{+}$and $20 \mathrm{~T}^{2+}$ are compared. $6 \mathrm{~T}^{+}$has two absorptions at 0.96 and $1.68 \mathrm{eV}$ with oscillator strengths of 0.53 and $1.70,{ }^{74}$ respectively. Table 3 and Figure 10 show that there are 5 absorptions for open-shell $12 \mathrm{~T}^{2+}$. Two features have very low oscillator strengths and two occur so close in energy that a spectrum with two absorptions is expected. Theoretical spectra of $6 \mathrm{~T}^{+}$and $12 \mathrm{~T}^{2+}$ are plotted together and compared to experiment in Figure 15. Both species have absorptions in close proximity of the experimental peaks. The difference between theoretical spectra of $6 \mathrm{~T}^{+}$and $12 \mathrm{~T}^{2+}$ is a reversal in relative oscillator strength. For $6 \mathrm{~T}^{+}$the low energy peak is much weaker than the high energy one. If the oscillator strengths of the close lying transitions at around $1.6 \mathrm{eV}$ of $12 \mathrm{~T}^{2+}$ were added, the two peaks at 0.77 and at $1.6 \mathrm{eV}$ should have about the same height, as observed experimentally. So the match between theory and experiment is better for $12 \mathrm{~T}^{2+}$ than for $6 \mathrm{~T}^{+}$.

Similar comparisons for $8 \mathrm{~T}^{+}$and $16 \mathrm{~T}^{2+}$, and $10 \mathrm{~T}^{+}$and $20 \mathrm{~T}^{2+}$, show that the first absorption of the dications is consistently about $0.18 \mathrm{eV}$ lower in energy. The middle peaks are energetically very similar for cations and dications, but the oscillator strengths are reversed. Finally, the high energy peaks of the longer species are more intense for the dications. Thus spectra of monocations and open-shell dications of twice the chain length are similar but not identical. Twisting $16 \mathrm{~T}^{2+}$ in the middle by $90^{\circ}$ resolves the differences compared to $8 \mathrm{~T}^{+}$. The reason is that for biradicals only HOMO and LUMO localized on one side of the chain whereas lower and higher lying $\pi$-orbitals remain delocalized. Thus transitions involving these orbitals are different for long biradicals and short monocations. 
The argument for disproportionation seems plausible at first glance; however, it is contradictory upon closer inspection. To favor $12 \mathrm{~T}^{2+}$ over $12 \mathrm{~T}^{+}$, there should be a stabilization of two charges on one chain. other words, for the disproportionation reaction

$$
212 \mathrm{~T}^{+} \rightarrow 12 \mathrm{~T}^{2+}+12 \mathrm{~T}
$$

To go to completion, it should be exothermic by $\sim 3 \mathrm{kcal} / \mathrm{mol}$. If the reaction energy was between $\pm 3 \mathrm{kcal} / \mathrm{mol}$, a mixture of all three species would be observed. Beyond that, no disproportionation should occur. That the two charges separate into two polarons on one chain should be evidence that there is no stabilization between them; otherwise, they would bind into a bipolaron. Therefore, there seems to be no driving force for a disproportionation. At the B3P86-30\%/CEP-31g* level in the gas phase, disproportionation of $12 \mathrm{~T}^{+}$is very endothermic, $\sim 32$ $\mathrm{kcal} / \mathrm{mol}$. In the presence of counterions $\left(\mathrm{Cl}_{3}{ }^{-}\right)$and solvent $\left(\mathrm{CH}_{2} \mathrm{Cl}_{2}\right)$, the reaction enthalpy decreases to $+2.4 \mathrm{kcal} / \mathrm{mol}$. This energy difference in favor of $12 \mathrm{~T}^{+}$indicates that at the first doping stage, very little dication should be present. It seems plausible that the reaction becomes energy neutral in the infinite chain limit, but there is no indication that it will ever become exothermic enough to account for a complete absence of $12 \mathrm{~T}^{+}$ upon doping. Note that an exothermic reaction would also imply the second ionization potential of $12 \mathrm{~T}$ to be lower than the first, a very unusual behavior for an organic molecule.

\section{Conclusions}

TDDFT with hybrid functionals predicts reliable excitation energies for charged oligothiophene. There is no indication that TDB3P86-30\% excitation energies deteriorate at long conjugation lengths. This is confirmed by the good agreement of predicted and experimental spectra for mono- and dications even for long oligomers.

Doping of OTs produces first monocations and then dications. Oligothiophene dications with chain lengths of 4-20 rings have open-shell biradical ground states, which means that DFT predicts formation of polaron pairs rather than bipolarons upon doping. Comparison with experiment confirms this assignment as only spectra of biradicals agree with experiment. For long chains above $\sim 20$ rings, triplet and singlet states are degenerate.

Theory predicts that spectra of oligomers with more than 9 rings display additional (higher energy) sub-band transitions that grow rapidly in oscillator as chain lengths increase. This finding coincides with experimental observations of changes in spectra between chain lengths of 9 and 12 rings. Thus according to theoretical results, no disproportionation has to be invoked to account for the difference between the spectra of lightly doped 9T and $12 \mathrm{~T}$.

Disproportionation of $12 \mathrm{~T}^{+}$into $12 \mathrm{~T}^{2+}$ and $12 \mathrm{~T}$ is endothermic in solution and in the presence of counterions. It is therefore unlikely that no radical cation is formed upon doping of $12 \mathrm{~T}$. Because the repulsion between the two charges is small and because this repulsion decreases with chain length, polaron pairs on the same chain can form in polymers at higher doping levels.

The very strong high energy sub-band absorptions of monocations and closed-shell dications are indicative of defect delocalization. Inclusion of counterions that localize the defects or dissociation into two shorter polarons changes energies and reduces oscillator strengths of these peaks.

Acknowledgment. I thank TÜBITAK for funding and Bilkent University and the Super Computer Center in Juelich for computational resources. I am grateful to Yavuz Dede of Middle
East Technical University for calculating the excitation energies of the bithiophene dication at the CASSCF and MCQDPT2 levels with GAMESS. I wish to thank Dr. Michael Bendikov of the Weizmann Institute of Sciences for helpful discussions.

\section{References and Notes}

(1) Chiang, C. K.; Fincher, C. R.; Park, Y. W.; Heeger, A. J.; Shirakawa, H.; Louis, E. J.; Gau, S. C.; MacDiarmid, A. G. Phys. Rev. Lett. 1977, 39, 1098.

(2) Shirakawa, H.; Louis, F. J.; MacDiarmid, A. G.; Chiang, C. K.; Heeger, A. J. J. Chem. Soc., Chem. Commun. 1977, 578.

(3) Chiang, C. K.; Druy, M. A.; Gau, S. C.; Heeger, A. J.; Louis, E. J.; MacDiarmid, A. G.; Park, Y. W.; Shirakawa, H. J. Am. Chem. Soc. 1978, 100, 1013

(4) Chiang, C. K.; Gau, S. C.; Fincher, C. R.; Park, Y. W.; MacDiarmid, A. G.; Heeger, A. J. Appl. Phys. Lett. 1978, 33, 18.

(5) Diaz, A. F. Chem. Scr. 1981, 17, 142.

(6) Tourillon, G.; Garnier, F. J. Electroanal. Chem. 1982, 135, 173.

(7) Kaneto, K.; Yoshino, K.; Inuishi, Y. Solid State Commun. 1983, $46,389$.

(8) Tourillon, G.; Garnier, F. J. Phys. Chem. 1983, 87, 2289.

(9) Chung, T.-C.; Kaufman, J. H.; Heeger, A. J.; Wudl, F. Phys. Rev. $B$ 1984, 30, 702 .

(10) Chen, J.; Heeger, A. J.; Wudl, F. Solid State Commun. 1986, 58, 251.

(11) Brédas, J. L.; Scott, J. C.; Yakushi, K.; Street, G. B. Phys. Rev. B 1984, 30, 1023.

(12) Brédas, J. L.; Street, G. B. Acc. Chem. Res. 1985, 18, 309.

(13) Evans, C. H.; Scaiano, J. C. J. Am. Chem. Soc. 1990, 112, 2694.

(14) Fichou, D.; Xu, B.; Horowitz, G.; Garnier, F. Synth. Met. 1991, $41,463$.

(15) Caspar, J. V.; Ramamurthy, V.; Corbin, D. R. J. Am. Chem. Soc. 1991, 113, 600 .

(16) Zinger, B.; Mann, K. R.; Hill, M. G.; Miller, L. L. Chem. Mater. 1992, 4, 1113 .

(17) Hill, M. G.; Penneau, J.-F.; Zinger, B.; Mann, K. R.; Miller, L. L. Chem. Mater. 1992, 4, 1106.

(18) Hill, M. G.; Mann, K. R.; Miller, L. L.; Penneau, J.-F. J. Am. Chem. Soc. 1992, 114, 2728.

(19) Guay, J.; Kasai, P.; Diaz, A.; Wu, R.; Tour, J. M.; Dao, L. H. Chem. Mater. 1992, 4, 1097.

(20) Guay, J.; Diaz, A.; Wu, R.; Tour, J. M.; Dao, L. H. Chem. Mater. 1992, 4, 254

(21) Hotta, S.; Waragai, K. J. Phys. Chem. 1993, 97, 7427.

(22) Bäuerle, P.; Segelbacher, U.; Maier, A.; Mehring, M. J. Am. Chem.

Soc. 1993, 115, 10217.

(23) Wintgens, V.; Valat, P.; Garnier, F. J. Phys. Chem. 1994, 98, 228.

(24) Janssen, R. A. J.; Moses, D.; Sariçiftci, N. S. J. Chem. Phys. 1994, 101,9519

(25) Horowitz, G.; Yassar, A.; von Bardeleben, H. J. Synth. Met. 1994, $62,245$.

(26) Nessakh, B.; Horowitz, G.; Garnier, F.; Deloffre, F.; Srivastava, P.; Yassar, A. J. Electroanal. Chem. 1995, 399, 97.

(27) Furukawa, Y. Synth. Met. 1995, 69, 629.

(28) Yu, Y.; Gunic, E.; Zinger, B.; Miller, L. L. J. Am. Chem. Soc. 1996, 118, 1013

(29) Sato, M.; Hiroi, M. Polymer 1996, 37, 1685.

(30) Miller, L. L.; Mann, K. R. Acc. Chem. Res. 1996, 29, 417.

(31) Tschunky, P.; Heinze, J.; Smie, A.; Engelmann, G.; Kossmehl, G. J. Electroanal. Chem. 1997, 433, 223.

(32) Graf, D. D.; Duan, R. G.; Campbell, J. P.; Miller, L. L.; Mann, K. R. J. Am. Chem. Soc. 1997, 119, 5888.

(33) Nakanishi, H.; Sumi, N.; Aso, Y.; Otsubo, T. J. Org. Chem. 1998, 63,8632 .

(34) van Haare, J. A. E. H.; Havinga, E. E.; van Dongen, J. L. J.; Janssen, R. A. J.; Cornil, J.; Brédas, J. L. Chem. Eur. J. 1998, 4, 1509.

(35) Otsubo, T.; Nakanishi, H.; Aso, Y. Synth. Met. 1999, 101, 604.

(36) Harima, Y.; Tang, H.; Zhu, L.; Yamashita, K.; Ohshita, J.; Kunai, A. J. Electroanal. Chem. 1999, 472, 157.

(37) Nakanishi, H.; Sumi, N.; Ueno, S.; Takimiya, K.; Aso, Y.; Otsubo, T.; Komaguchi, K.; Shiotani, M.; Ohta, N. Synth. Met. 2001, 119, 413.

(38) Furukawa, Y. J. Phys. Chem. 1996, 100, 15644.

(39) Glenis, S.; Tourillon, G.; Garnier, F. Thin Solid Films 1984, $122,9$.

(40) Kaneto, K.; Kohno, Y.; Yoshino, K. Solid State Commun. 1984, $51,267$.

(41) Tourillon, G.; Garnier, F. J. Electroanal. Chem. 1984, 161, 407.

(42) Kaneto, K.; Hayashi, S.; Ura, S.; Yoshino, K. J. Phys. Soc. Jpn. 1985, 54, 1146.

(43) Bertho, D.; Jouanin, C. Phys. Rev. B 1987, 35, 626.

(44) Brédas, J. L.; Wudl, F.; Heeger, A. J. Solid State Commun. 1987, 63, 577.

(45) Kaneto, K. Synth. Met. 1987, 18, 133. 
(46) Yumoto, Y.; Morishita, K.; Yoshimura, S. Synth. Met. 1987, 18, 203. (47) Schärli, M.; Kiess, H.; Harbeke, G. Synth. Met. 1988, 22, 317. (48) Zotti, G.; Schiavon, G. Synth. Met. 1989, 31, 347.

(49) Yokonuma, N.; Furukawa, Y.; Tasumi, M.; Kuroda, M.; Nakayama, J. Chem. Phys. Lett. 1996, 255, 431.

(50) Zotti, G. Synth. Met. 1998, 97, 267.

(51) Saeki, A.; Seki, S.; Koizumi, Y.; Sunagawa, T.; Ushida, K.;

Tagawa, S. J. Phys. Chem. B 2005, 109, 10015

(52) Roncali, J. Chem. Rev. 1992, 92, 711.

(53) Roncali, J. Chem. Rev. 1997, 97, 173.

(54) Skotheim, T. A. Handbook of Conducting Polymers; Marcel Dekker: New York, 1986.

(55) Handbook of Conducting Polymers, 2nd ed.;Skotheim, T. A., Elsenbaumer, R. L., Reynolds, J. R. Eds.; Marcel Dekker, Inc.; New York, 1997. (56) Patil, A. O.; Heeger, A. J.; Wudl, F. Chem. Rev. 1988, 88, 183

(57) Brédas, J. L.; Chance, R. R.; Silbey, R. Phys. Rev. B 1982, 26, 5843 .

(58) Brédas, J. L.; Thémans, B.; André, J.-M.; Chance, R. R.; Silbey, R. Synth. Met. 1984, 9, 265.

(59) Cornil, J.; Beljonne, D.; Brédas, J. L. J. Chem. Phys. 1995, 103, 842.

(60) Cornil, J.; Beljonne, D.; Brédas, J. L. J. Chem. Phys. 1995, 103, 834

(61) Ye, A.; Shuai, Z.; Beljonne, D.; Brédas, J. L. Synth. Met. 2003, 137, 1077.

(62) Ye, A.; Shuai, Z.; Kwon, O.; Brédas, J. L.; Beljonne, D. J. Chem. Phys. 2004, 121, 5567

(63) Grozema, F. C.; Candeias, L. P.; Swart, M.; van Duijnen, P. T.; Wildeman, J.; Hadziioanou, G.; Siebbeles, L. D. A.; Warman, J. M. J. Chem. Phys. 2002, 117, 11366.

(64) Ma, H.; Liu, C.; Jiang, Y. J. Chem. Phys. 2005, 123, 843031.

(65) Bauernschmitt, R.; Ahlrichs, R. Chem. Phys. Lett. 1996, 256, 454

(66) Casida, M. E.; Jamorski, C.; Casida, K. C.; Salahub, D. R. J. Chem. Phys. 1998, 108, 4439

(67) Luo, Y.; Norman, P.; Ruud, K.; Ågren, H. Chem. Phys. Lett. 1998 285,160 .

(68) Stratmann, R. E.; Scuseria, G. E.; Frisch, M. J. J. Chem. Phys. 1998, 109,8218 .

(69) Hirata, S.; Head-Gordon, M. Chem. Phys. Lett. 1999, 302, 375.

(70) Hirata, S.; Head-Gordon, M.; Bartlett, R. J. J. Chem. Phys. 1999, 111,10774

(71) Salzner, U. Curr. Org. Chem. 2004, 8, 569.

(72) Salzner, U. Conjugated Organic Polymers: From Bulk to Molecular Wire. In Handbook of Theoretical and Computational Nanotechnology; Rieth, M., Schommers, W. Eds.; ASP: Los Angeles, 2006; Vol. 8; pp 203.

(73) Salzner, U. J. Chem. Theor. Comput. 2007, 3, 219.

(74) Salzner, U. J. Chem. Theor. Comput. 2007, 3, 1143.

(75) Hsu, C.-P.; Hirata, S.; Head-Gordon, M. J. Phys. Chem. A 2001 105,451

(76) Fabian, J. Theor. Chem. Acc. 2001, 106, 199. 5543

(77) Cai, Z.-L.; Sendt, K.; Reimers, J. R. J. Chem. Phys. 2002, 117,

(78) Parac, M.; Grimme, S. Chem. Phys. 2003, 292, 11.

(79) Hirata, S.; Head-Gordon, M.; Szczepanski, J.; Vala, M. J. Phys. Chem. A 2003, 107, 4940.

(80) Grozema, F. C.; van Duijnen, P. T.; Siebbeles, L. D.; Goossens, A.; Leeuw, S. W. J. Phys. Chem. B 2004, 108, 16139.

(81) Dierksen, M.; Grimme, S. J. Phys. Chem. A 2004, 108, 10225.

(82) Dierksen, M.; Grimme, S. J. Chem. Phys. 2004, 120, 3544.

(83) Dierksen, M.; Grimme, S. J. Chem. Phys. 2005, 122, 244101.

(84) Jacquemin, D.; Perpète, E. A.; Scalmani, G.; Frisch, M. J.; Assfeld,

X.; Ciofini, I.; Adamo, C. J. Chem. Phys. 2006, 125, 164324.

(85) Guillaume, M.; Champagne, B.; Zutterman, F. J. Phys. Chem. A 2006, $110,13007$.

(86) Magyar, R. J.; Tretiak, S. J. Chem. Theory Comput. 2007, 3, 976.

(87) Dreuw, A.; Head-Gordon, M. Chem. Rev. 2005, 105, 4009.

(88) Fabiano, E.; Della Sala, F.; Cingolani, R.; Weimer, M.; Görling,

A. J. Phys. Chem. A 2005, 109, 3078.

(89) Starcke, J. H.; Wormit, M.; Schirmer, J.; Dreuw, A. Chem. Phys.

2006, 329, 39 5380 .

(90) Gao, Y.; Liu, C.-G.; Jiang, Y.-S. J. Phys. Chem. A 2002, 106,

(91) Rubio, M.; Merchán, M.; Ortí, E.; Roos, B. O. Chem. Phys. Lett. 1996, 248, 321

(92) Kawashima, Y.; Nakayama, K.; Nakano, H.; Hirao, H. Chem. Phys. Lett. 1997, 267, 82

(93) Beljonne, D.; Shuai, Z.; Serrano-Andrés, L.; Brédas, J. L. Chem. Phys. Lett. 1997, 279, 1. 66,157

(94) Nakayama, K.; Nakano, H.; Hirao, K. Int. J. Quantum Chem. 1998

(95) Keszthelyi, T.; Grage, M. M.-L.; Offersgard, J. F.; Wilbrandt, R.; Svendsen, C.; Sonnich Mortensen, O.; Pedersen, J. K.; Jensen, H. J. A. J. Phys. Chem. A 2000, 104, 2808.
(96) Bally, T.; Hrovat, D. A.; Thatcher Borden, W. Phys. Chem. Chem. Phys. 2000, 2, 3363

(97) Rubio, M.; Ortí, E.; Pou-Amerigo, R.; Merchán, M. J. Phys. Chem. A 2001, 105, 9788.

(98) Scherlis, D. A.; Marzari, N. J. Phys. Chem. B 2004, 108, 17791.

(99) Kurashige, Y; Nakano, H.; Nakao, Y; Hirao, K. Chem. Phys.

Lett. 2004, 400, 425

(100) Zade, S. S.; Bendikov, M. J. Phys. Chem. B 2006, 110, 15839. (101) Singh-Miller, N. E.; Scherlis, D. A.; Marzari, N. J. Phys. Chem. $B$ 2006, 110, 24822 .

(102) Serrano-Andrés, L.; Merchán, M.; Nebot-Gil, I.; Lindh, R.; Roos, B. O. J. Chem. Phys. 1993, 98, 3151 .

(103) Serrano-Andrés, L.; Lindh, R.; Roos, B. O.; Merchán, M. J. Phys. Chem. 1993, 97, 9360.

(104) Nakano, H.; Tsuneda, T.; Hashimoto, T.; Hirao, K. J. Chem. Phys. 1996, 104, 2312.

(105) Hirao, K.; Nakano, H.; Nakayama, K.; Dupuis, M. J. Chem. Phys. 1996, $105,9227$.

(106) Luo, Y.; Ågren, H.; Stafström, S. J. Chem. Phys. 1994, 98, 7782.

(107) Hutchison, G. R.; Ratner, M.; Marks, T. J. J. Phys. Chem. A 2002, $106,10596$.

(108) van Faassen, M.; de Boeji, P. L. J. Chem. Phys. 2004, 120, 8355. (109) van Faassen, M.; de Boeji, P. L. J. Chem. Phys. 2004, 121, 10707. (110) Hirata, S.; Lee, T. J.; Head-Gordon, M. J. Chem. Phys. 1999, 111, 8904

(111) Zade, S. S.; Bendikov, M. Chem. Eur. J. 2007, 13, 3688.

(112) Taliani, C.; Blinov, L. M. Adv. Mater. 1996, 8, 353.

(113) Becke, A. D. J. Chem. Phys. 1993, 98, 5648.

(114) Perdew, J. P. Phys. Rev. B 1986, 33, 8822

(115) Salzner, U.; Lagowski, J. B.; Pickup, P. G.; Poirier, R. A. J. Comput. Chem. 1997, 18, 1943.

(116) Salzner, U.; Lagowski, J. B.; Pickup, P. G.; Poirier, R. A. J. Phys. Chem. A 1998, 102, 2572.

(117) Schlegel, H. B.; Robb, M. A. Chem. Phys. Lett. 1982, 93, 43.

(118) Bernardi, F.; Bottini, A.; McDougall, J. J. W.; Robb, M. A.; Schlegel, H. B. Faraday Symp. Chem. Soc. 1984, 19, 137.

(119) Yamamoto, N.; Vreven, T.; Robb, M. A.; Frisch, M. J.; Schlegel, H. B. Chem. Phys. Lett. 1996, 250, 373.

(120) Frisch, M. J.; Ragazos, I. N.; Robb, M. A.; Schlegel, H. B. Chem. Phys. Lett. 1992, 189, 524.

(121) Nakano, H. J. Chem. Phys. 1993, 99, 7983.

(122) Stevens, W.; Basch, H.; Krauss, J. J. Chem. Phys. 1984, 81, 6026.

(123) Stevens, W. J.; Krauss, M.; Basch, H.; Jasien, P. G. Can. J. Chem. 1992, 70, 612 .

(124) Cundari, T. R.; Stevens, W. J. J. Chem. Phys. 1993, 98, 5555.

(125) Cossi, M.; Cammi, R.; Tomasi, J. Chem. Phys. Lett. 1996, 255, 327.

(126) Schmidt, M. W.; Baldridge, K. K.; Boatz, J. A.; Elbert, S. T.; Gordon, M. S.; Jensen, J. H.; Koseki, S.; Matsunaga, N.; Nguyen, K. A.; Su, S. J.; Windus, T. L.; Dupuis, M.; Montgomery, J. A. J. Comput. Chem. 1993, 14, 1347.

(127) Frisch, M. J; Trucks, G. W ; Schlegel, H. B ; Scuseria, G. E; Robb, M. A.; Cheeseman, J. R.; Montgomery, J. A., Jr.; Vreven, T.; Kudin, K. N.; Burant, J. C.; Millam, J. M.; Iyengar, S. S.; Tomasi, J.; Barone, V.; Mennucci, B.; Cossi, M.; Scalmani, G.; Rega, N.; Petersson, G. A.; Nakatsuji, H.; Hada, M.; Ehara, M.; Toyota, K.; Fukuda, R.; Hasegawa, J.; Ishida, M.; Nakajima, T.; Honda, Y.; Kitao, O.; Nakai, H.; Klene, M.; Li, X.; Knox, J. E.; Hratchian, H. P.; Cross, J. B.; Bakken, V.; Adamo, C.; Jaramillo, J.; Gomperts, R.; Stratmann, R. E.; Yazyev, O.; Austin, A. J.; Cammi, R.; Pomelli, C.; Ochterski, J. W.; Ayala, P. Y.; Morokuma, K.; Voth, G. A.; Salvador, P.; Dannenberg, J. J.; Zakrzewski, V. G.; Dapprich, S.; Daniels, A. D.; Strain, M. C.; Farkas, O.; Malick, D. K.; Rabuck, A. D.; Raghavachari, K.; Foresman, J. B.; Ortiz, J. V.; Cui, Q.; Baboul, A. G.; Clifford, S.; Cioslowski, J.; Stefanov, B. B.; Liu, G.; Liashenko, A.; Piskorz, P.; Komaromi, I.; Martin, R. L.; Fox, D. J.; Keith, T.; Al-Laham, M. A.; Peng, C. Y.; Nanayakkara, A.; Challacombe, M.; Gill, P. M. W.; Johnson, B.; Chen, W.; Wong, M. W.; Gonzales, C.; Pople, J. A. Gaussian 03, revision D.01; Gaussian, Inc.: Wallingford, CT, 2004.

(128) Birnbaum, D.; Fichou, D.; Kohler, B. E. J. Chem. Phys. 1992, 96,165 .

(129) D’Amico, K. L.; Manos, C.; Christensen, R. L. J. Am. Chem. Soc. 1980, 102, 1777 .

(130) Colditz, R.; Grebner, D.; Helbig, M.; Rentsch, S. Chem. Phys. 1995, 201, 309 .

(131) Pariser, R. J. Chem. Phys. 1956, 24, 250.

(132) Dreuw, A.; Head-Gordon, M. J. Am. Chem. Soc. 2004, 126, 4007.

(133) Tozer, D. J.; Handy, N. C. J. Chem. Phys. 1998, 109, 10180

(134) Sanchez-Carrera, R. S.; Coropceanu, V.; da Silva, D. A.; Friedlein, R.; Osikowicz, W.; Murdey, R.; Suess, C.; Salaneck, W. R.; Bredas, J. L. J. Phys. Chem. B 2006, 110, 18904.

JP800606M 